\title{
Sodium Chloride and Water Transport in the Medullary Thick Ascending Limb of Henle
}

\author{
EVIDENCE FOR ACTIVE CHLORIDE TRANSPORT
}

\author{
Antonino S. Rocha and Juha P. Kokкo \\ From the Department of Internal Medicine, The University of Texas South- \\ western Medical School, Dallas, Texas 75235
}

A B S T R A C T Transport of $\mathrm{NaCl}$ and water was examined in the rabbit medullary thick ascending limb of Henle (ALH) by perfusing isolated segments of these nephrons in vitro. Osmotic water permeability was evaluated by perfusing tubules against imposed osmotic gradients. In these experiments the net transport of fluid remained at zero when segments of thick ALH were perfused with isotonic ultrafiltrate in a bath of rabbit serum in which the serum osmolality was increased by the addition of either $239 \pm 8$ mosmol/liter of raffinose or $232 \pm 17$ mosmol of $\mathrm{NaCl}$ indicating that the thick ascending limb of Henle is impermeant to osmotic flow of water. When these tubules were perfused at slow rates with isosmolal ultrafiltrate of same rabbit serum as used for the bath, the effluent osmolality was consistently lowered to concentrations less than the perfusate and the bath. That this decrease in collected fluid osmolality represented salt transport was demonstrated in a separate set of experiments in which it was shown that the sodium and chloride concentrations decreased to $0.79 \pm 0.02$ and $0.77 \pm 0.02$ respectively when compared with the perfusion fluid concentrations. In each instance the simultaneously determined transtubular potential difference (PD) revealed the lumen to be positive with the magnitude dependent on the perfusion rate. At flow rates above $2 \mathrm{nl} \cdot \mathrm{min}^{-1}$, the mean transtubular PD was stable and equal to $6.70 \pm 0.34 \mathrm{mv}$. At stop-flow conditions this $\mathrm{PD}$ became more positive. Ouabain and cooling reversibly decreased the magnitude of this $\mathrm{PD}$. The transtubular $\mathrm{PD}$ remained positive, $3.3 \pm$ $0.2 \mathrm{mV}$, when complete substitution of $\mathrm{Na}$ by choline was carried out in both the perfusion fluid and the bathing media. These results are interpreted to indicate that

Dr. Rocha is a Research Fellow of Fundacao de Amparo A Pesquisa do Estado de Sau Paulo.

Received for publication 8 August 1972 and in revised form 24 October 1972. the active transport process is primarily an electrogenic chloride mechanism. The isotopic permeability coefficient for $\mathrm{Na}$ was $6.27 \pm 0.38 \times 10^{-5} \mathrm{~cm} \cdot \mathrm{s}^{-1}$ indicating that the thick ALH is approximately as permeable to $\mathrm{Na}$ as the proximal convoluted tubule. The chloride permeability coefficient for the thick ALH was 1.06 $\pm 0.12 \times 10^{-5} \mathrm{~cm} \cdot \mathrm{s}^{-1}$ which is significantly less than the chloride permeability of the proximal tubule.

These data demonstrate that the medullary thick ascending limb of Henle is water impermeable while having the capacity for active outward solute transport as a consequence of an electrogenic chloride pump. The combination of these characteristics allows this segment to generate a dilute tubular fluid and participate as the principal energy source for the overall operation of the countercurrent multiplication system.

\section{INTRODUCTION}

The formation of concentrated urine is a function of the counter-current multiplication system. The operation of the system must have a source of energy. Most previous studies have suggested that active outward transport of sodium salts by the entire length of the ascending limb of Henle $(\mathrm{ALH})^{1}$ is a source of this energy. Support for this concept has come indirectly from those micropuncture studies which have shown that the fluid in early distal tubule is hypoosmolal with respect to adjacent plasma (1-4). However, direct studies concerning the nature of these transport processes have not been reported due to the inaccessibility of the thick ascending limb of Henle to micropuncture techniques.

The present study was designed to examine the characteristics of sodium chloride and water transport

\footnotetext{
${ }^{1}$ Abbreviations used in this paper: ALH, ascending limb of Henle, TAL, thick ascending limb.
} 

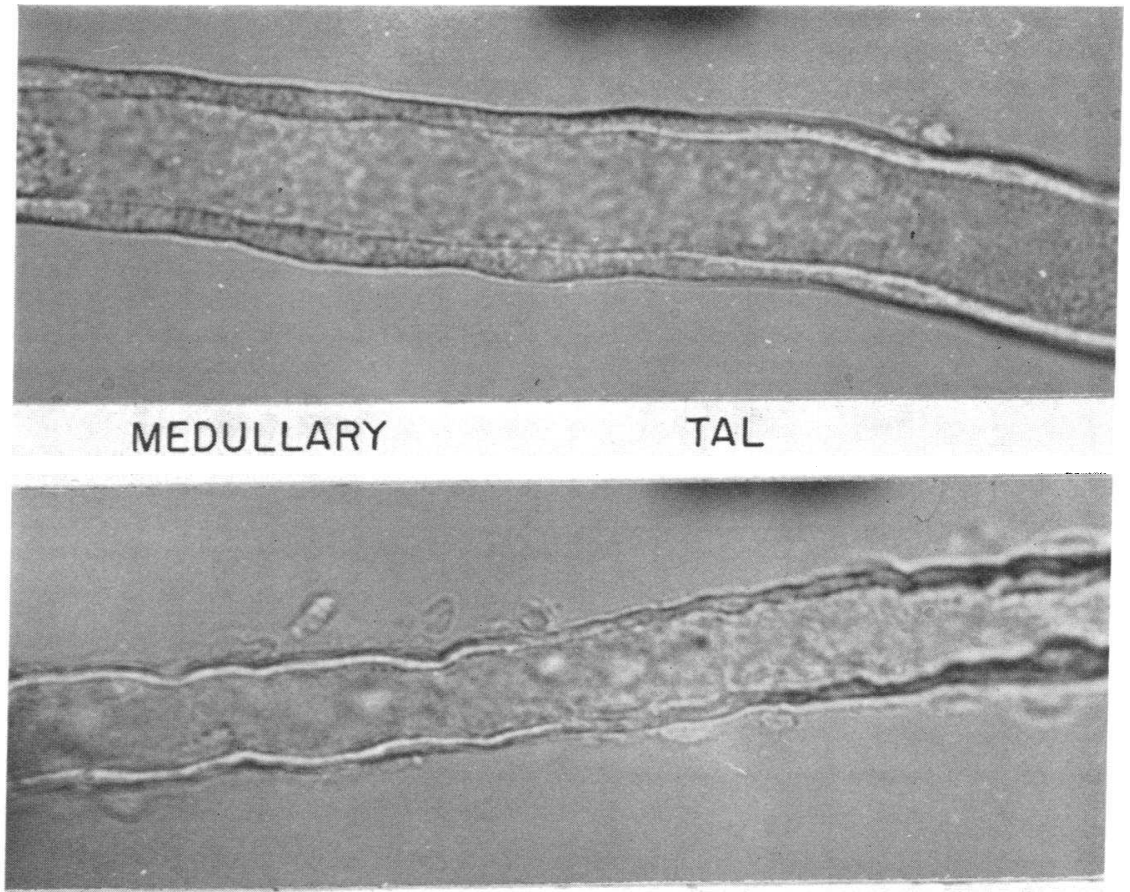

CORTICAL

TAL

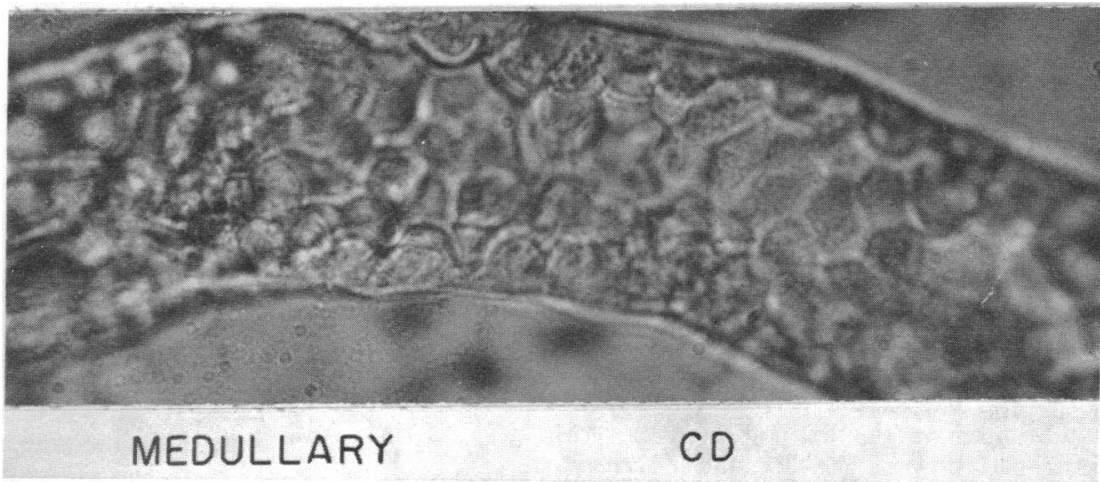

FIgURE 1 Magnification $(\times 200)$ of a perfused outer medullary thick ascending limb of Henle (TAL), top panel; cortical thick ascending limb of Henle (TAL), middle panel; and, outer medullary collecting duct (CD), bottom panel. Note the clear-cut anatomical differences. Mean respective inside and outside diameters of the thick medullary ascending limb of Henle was $24.5 \pm 0.5$ and $33.1 \pm 0.5 \mu \mathrm{m}$. The cells of the medullary TAL are obviously much thicker than those of the cortical thick ascending limb and the epithelium of previously described thin descending limb of Henle (5). At this magnification the thin ascending limb of Henle is similar in appearance to the thin descending limb of Henle and is clearly different from the thick ascending limb. Also note the contrast of the medullary TAL when compared with the cuboidal cells of the outer medullary collecting duct.

by the medullary thick ascending limb of Henle utilizing the direct technique of perfusing isolated segments of rabbit nephrons in vitro. In these studies, the osmotic water permeability coefficient, transtubular potential difference (PD), the effect of ouabain on transtubular $\mathrm{PD}$, isotopic permeability for $\mathrm{Na}$ and $\mathrm{Cl}$, unidirectional fluxes of $\mathrm{Na}$ and $\mathrm{Cl}$, and the ability to transport salt against concentration gradients were all evaluated.

\section{METHODS}

Isolated segments of thick ascending limb of Henle (0.6$1.6 \mathrm{~mm}$ in length), obtained from the outer medulla of female New Zealand rabbits, were perfused by the general technique previously described (5). The rabbits had free access to water and standard laboratory chow diet before decapitation. The nephrons were dissected free in chilled dishes of rabbit serum without use of collagenase or other enzymatic agents. As shown in Fig. 1 the medullary thick 
ascending limb (TAL) had a very distinctive morphologic appearance that permitted it to be easily distinguished from the cortical thick ascending limb, medullary collecting duct, and the thin limbs of Henle's loop. Unless otherwise specified, the tubules were perfused with isosmolal ultrafiltrate of the same rabbit serum as the bath. The perfusion rate was controlled by hydrostatic pressure. Sylgard 184 (Dow Corning Corp., Midland, Mich.) was used at the tissue/glass junction of both the collecting and perfusion pipettes to provide excellent electrical and isotopic seals. [ $\left.{ }^{125} \mathrm{I}\right]$ Iodothalamate was used as the volume marker. Net reabsorption was calculated by previously published techniques (6):

$$
C=\frac{V_{i}-V_{0}}{L}
$$

where $V_{\mathfrak{t}}$ is calculated by dividing the ${ }^{125} \mathrm{I}$ counts per minute of the collected fluid by ${ }^{125} \mathrm{I}$ counts/minute per nanoliter of perfusion fluid and by time of the collection period. $V_{0}$ is obtained directly by a calibrated constant-bore collection pipette. $L$ is the length of the tubule, and $C$ is the absolute volume of fluid transported in nanoliters/millimeter per minute and is positive if fluid is absorbed and negative if fluid is secreted.

The hydraulic conductivity of water $\left(L_{p}\right)$ was determined by measuring net fluid movement in response to an imposed osmotic gradient of $\mathrm{NaCl}$ or raffinose. Control periods were obtained by perfusing with isosmolal ultrafiltrate of same rabbit serum as used in the bath. After the control periods, the bath osmolality was raised by addition of either $232 \pm 17$ mosmol/liter $\mathrm{NaCl}$ or $230 \pm 15 \mathrm{mosmol} /$ liter raffinose to the bath. The $L_{p}$ was calculated by the following equation:

$$
L_{p}=\frac{J_{v}}{\Delta \pi}
$$

where $J_{0}$ is the net-induced transmembrane water flow secondary to the imposed osmotic gradient, $\Delta \pi$, between the bath and the perfusate. The collected fluid osmolality was measured in each case by the freezing point technique previously described in detail (7).

To evaluate net transport of sodium and chloride, ${ }^{2} \mathrm{Na}$ and ${ }^{36} \mathrm{Cl}$ were added to isosmolal ultrafiltrate of rabbit serum; a fraction of this fluid was used as the perfusion solution, while the remainder was used as the bathing medium. In this manner the specific activities of the $\mathrm{Na}$ and $\mathrm{Cl}$ were identical in both the perfusate and the bathing fluids. Thus, a change in the respective counts per nanoliter of collected fluid reflects a change in the chemical concentration of $\mathrm{Na}$ and $\mathrm{Cl}$, assuming that ${ }^{24} \mathrm{Na}$ and ${ }^{88} \mathrm{Cl}$ are perfect tracers. The bathing fluid counts per nanoliter were closely monitored, and kept constant by the addition of appropriate amounts of water to the bath (usually about $20 \mu 1 / 10 \mathrm{~min}$ ) to counteract the effects of evaporation. The perfusion rate in these experiments was kept as slow as possible (mean $(0.8 \mathrm{nl} /$ $\mathrm{min}$ ) to give maximum contact time for generation of the concentration gradients. Collection periods in each case were over $30 \mathrm{~min}$ to obtain a large enough sample to insure statistically significant isotopic counts. Sufficient amounts of isotopes were added that the collected sample counts per minute were always greater than five times the background counts per minute.

The capacity for net solute transport was examined in a separate set of experiments in which individual tubules were perfused at varying rates from less than $2 \mathrm{nl} / \mathrm{min}$ to about $10 \mathrm{nl} / \mathrm{min}$. The perfusate in each experiment was isosmolal ultrafiltrate of the same rabbit serum as used for bath. The collected fluid osmolality was measured in each case and compared with the simultaneously measured perfusate and bath osmolalities.

The transtubular PD was measured by techniques similar to those we have previously employed in studying the proximal tubule (8). In these experiments, equivalent bridges of 300 mosmol/liter Ringer's solution in $4 \%$ agar were connected to the end of the perfusion pipette and the bath. The other end of the bridges were submerged in a container with saturated $\mathrm{KCl}$ and Beckman (Beckman Instruments, Inc., Fullerton, Calif.) calomel half-cells. The circuit was completed through a Keithley 600-b (Keithley Instruments, Inc., Cleveland, Ohio) electrometer. The stability of the circuit was excellent with base-line drifts of less than 0.5 $\mathrm{mV}$ over 12 experimental periods. The inner diameter of the perfusion pipette was as large as possible $(15 \mu \mathrm{m})$ in order to eliminate dead space between tubule and pipette, and to keep the resistance of the circuit at less than $7 \mathrm{M \Omega}$.

Relative permeability characteristics of the thick ALH were evaluated electrochemically by measuring the resultant changes in transtubular PD from imposed ionic concentration gradients. In these experiments a control transtubular PD was obtained first by using the same artificial fluid as the perfusate and the bathing media. Table I. In the experimental period either $\mathrm{Na}^{+}$or $\mathrm{Cl}^{-}$was selectively and respectively replaced by choline or methyl sulfate, Table I, or $\mathrm{NaCl}$ either diluted or concentrated by either the addition of water or $\mathrm{NaCl}$ to the bath, Fig. 5 .

Apparent isotopic permeability coefficient for sodium $\left(P_{\mathrm{Na}}^{\prime}\right)$ and chloride $\left(P_{\mathrm{Cl}}^{\prime}\right)$ was obtained from the influx rate of ${ }^{22} \mathrm{Na}$ or ${ }^{36} \mathrm{Cl}$ added to the bath according to the expression (9) :

$$
P^{\prime}{ }_{\mathrm{Na}} \text { or } P_{\mathrm{Cl}}^{\prime}=\frac{V_{o}^{\prime}\left[R_{l}\right]}{A\left[R_{b}-R_{l}\right]}
$$

where $A$ is luminal surface area; $V_{0}$ collected volume in nanoliters per second; and $\left[R_{b}\right]$ and $\left[R_{l}\right]$ are concentration of the corresponding isotopes in the bath and collected fluids, respectively. $\left[\overline{R_{b}-R_{l}}\right]$ is the logarithmic mean concentration gradient between the bath and collected fluid isotope concentration. These experiments were performed using isosmolal ultrafiltrate as the perfusate, and regular rabbit serum as the bath. Because a transtubular PD exists under these conditions, as simultaneously measured, the apparent permeability coefficient, $P^{\prime}$, calculated by equation (3) must be corrected for the transtubular PD by the Hodgkin-Katz equation (10) to give the true permeability coefficient

$$
P=P_{i}^{\prime} \frac{R T\left(1-\exp \frac{Z F V}{R T}\right)}{V Z F[i]}
$$

where $P$ is the corrected permeability coefficient for each isotope; $i$ refers to the isotope in question; $P^{\prime}$ is the apparent isotopic permeability coefficient not corrected for transtubular $\mathrm{PD} ; Z$ is the valance of $\mathrm{Na}$ or $\mathrm{Cl}$ and is equal to $1 ; F$ is the Faraday constant; $R$ the gas constant; $T$ absolute temperature; $V$ is the transtubular $\mathrm{PD}$; and [i] is the concentration of $\mathrm{Na}$ or $\mathrm{Cl}$ at each side of the membrane.

Unidirectional fluxes for sodium $\Phi_{\mathrm{N}}$ and chloride $\Phi_{01}$ were estimated isotopically using isosmolal ultrafiltrate as the perfusate in a bath of rabbit serum. Three separate experimental protocols were carried out: (a) measurement of $\Phi_{\mathrm{Cl}}$ alone by determining the rate of disappearance of 
TABLE I

Composition of Various Artificial Solutions Which Were Used Either as Perfusion

Fluids or as Bathing Media

\begin{tabular}{|c|c|c|c|c|}
\hline & $\begin{array}{l}\text { Regular } \\
\text { artificial } \\
\text { solution }\end{array}$ & $\begin{array}{c}\text { Choline } \\
\text { chloride } \\
\text { solution, } 1\end{array}$ & $\begin{array}{c}\text { Choline } \\
\text { chloride } \\
\text { solution, } 2\end{array}$ & $\begin{array}{l}\text { Sodium } \\
\text { methyl } \\
\text { sulfate } \\
\text { solution }\end{array}$ \\
\hline $\mathrm{NaCl}$, mmol/liter & 105 & - & - & - \\
\hline $\mathrm{NaHCO}_{3}$, mmol/liter & 25 & 25 & - & 25 \\
\hline NaAc, mmol/liter & 10 & 10 & - & 10 \\
\hline $\mathrm{KCl}, \mathrm{mmol} /$ liter & 5 & 5 & - & 5 \\
\hline Alanine, mmol/liter & 5 & 5 & 5 & 5 \\
\hline Glucose, $\mathrm{mg} / 100 \mathrm{ml}$ & 150 & 150 & 150 & 150 \\
\hline $\mathrm{Na}_{2} \mathrm{HPO}_{4}, \mathrm{mmol} /$ liter & 4 & 4 & - & 4 \\
\hline $\mathrm{CaCl}_{2}, \mathrm{mmol} /$ liter & 1.8 & 1.8 & 1.8 & 1.8 \\
\hline $\mathrm{MgSO}_{4}, \mathrm{mmol} /$ liter & 1.0 & 1.0 & 1.0 & 1.0 \\
\hline $\mathrm{MgSO}_{4} \mathrm{mmol} /$ liter & 1.0 & 1.0 & 1.0 & 1.0 \\
\hline Choline $\mathrm{Cl}, \mathrm{mmol} /$ liter & - & 105 & 140 & - \\
\hline $\mathrm{NeCH}_{3} \mathrm{SO}_{4}, \mathrm{mmol} /$ liter & - & - & - & 100 \\
\hline $\mathrm{K}_{2} \mathrm{HPO}_{4}$, mmol/liter & - & - & 2 & - \\
\hline
\end{tabular}

${ }^{36} \mathrm{Cl}$ added to perfusate; $(b)$ simultaneous measurement of $\Phi_{\mathrm{Cl}}$ and $\Phi_{\mathrm{Na}}$ by determining rate of disappearance of ${ }^{24} \mathrm{Na}$ and ${ }^{36} \mathrm{Cl}$ added to the perfusate; and (c) simultaneous bidirectional sodium fluxes determinations by measuring the rate of transmembrane movement of ${ }^{22} \mathrm{Na}$ added to perfusate and ${ }^{24} \mathrm{Na}$ added to the bath. Sufficient concentrations of isotopes were added to insure counting rates at five times above the background.

The radioactivity of ${ }^{125} \mathrm{I},{ }^{22} \mathrm{Na}$, and ${ }^{24} \mathrm{Na}$ was measured using a Packard model 3365 (Packard Instrument Co., Inc., Downers Grove, Ill.) and ${ }^{36} \mathrm{Cl}$ was measured using a Packard model 2420 liquid scintillation counter. ${ }^{24} \mathrm{Na}$ was measured immediately after samples were obtained and corrected for decay time, while ${ }^{125} \mathrm{I},{ }^{22} \mathrm{Na}$, and ${ }^{26} \mathrm{Cl}$ were measured 15 days after measurement of ${ }^{24} \mathrm{Na}$ to allow for complete decay of ${ }^{24} \mathrm{Na}$. The sources of isotopes were: $\left[{ }^{125} \mathrm{I}\right]$ Iothalamate, (Glofil-125), Abbott Laboratories, North Chicago, Ill.; ${ }^{24} \mathrm{Na}$ and ${ }^{38} \mathrm{Cl}$, International Nuclear Corp., Irvine, Calif.; ${ }^{22} \mathrm{Na}$, New England Nuclear Corp., Boston Mass.

The results are expressed as mean \pm standard error. The data for each tubule are the mean of two to four collection periods per tubule depending on the experimental protocol.

\section{RESULTS}

Osmotic water permeability. The net movement of water secondary to an imposed osmotic gradient was studied under two circumstances. In the first set, 232 $\pm 17 \mathrm{mosmol} /$ liter osmotic gradient was established by the addition of $\mathrm{NaCl}$ to the bath while in the second set, $239 \pm 8$ mosmol raffinose was added to the bath, Table II. The osmolality of the collected fluid increased by $1.5 \pm 1.3 \%$ when raffinose was added to the bath and by $2.3 \pm 1.0 \%$ when $\mathrm{NaCl}$ was added to the bath. In neither case was there statistical difference between the perfusion and collection rate indicating that the thick ALH is impermeant to osmotic flow of water.
Net transport of sodium and chloride. Net transport of sodium and chloride was studied in eight tubules in which simultaneous transtubular PD was measured. All these studies were conducted at slow perfusion rates $(0.8 \pm 0.18 \mathrm{nl} / \mathrm{min})$ in order to magnify any concentration gradients that might be generated by active reabsorptive processes.

Under these conditions concentration of the volume marker remained unchanged. The calculated net reabsorption of water was $-0.02 \pm 0.01 \mathrm{nl} / \mathrm{min}$, which is not different from zero. The failure to demonstrate net water reabsorption is consistent with the demonstration that the thick ALH is impermeable to the osmotic flow of water.

On the other hand, significant net reabsorption of both sodium and chloride was observed; the transport rates were $0.028 \pm 0.008 \mathrm{neq} / \mathrm{mm} \cdot \mathrm{min}$ of sodium and $0.019 \pm 0.005 \mathrm{neq} / \mathrm{mm} \cdot \mathrm{min}$ of chloride. As a results of net salt reabsorption out of the water-impermeant thick ALH, the concentration of both sodium and chloride fell below their respective concentrations in the bathing fluid (Table III).

The ionic distribution on two sides of a given membrane will be influenced by the transtubular PD. In absence of active transport, the ratio of the ionic concentrations can be predicted by the Nernst equation: $E=-61.5 \log C 1 / C 2$ where $C 1$ and $C 2$ are concentrations of ions on the two sides of a membrane. The failure of an ionic species to distribute as predicted from this equation suggests the presence of an active transport process for this ion. From the determined concentration gradients (Table III), the calculated equilibrium potential chloride is $-6.94 \pm 0.77 \mathrm{mV}$ 
TABLE II

Osmotic Water Permeability $\left(L_{p}\right)$

\begin{tabular}{|c|c|c|c|c|c|c|}
\hline Exp. & $\begin{array}{c}\text { Tubular } \\
\text { area }\end{array}$ & $V_{i}$ & $J_{n}$ & $\begin{array}{l}\text { Osmotic } \\
\text { gradient }\end{array}$ & $\begin{array}{l}\text { Osmol. increase in } \\
\text { the collected } \\
\text { fluid }\end{array}$ & $I_{p}$ \\
\hline & $\mathrm{cm}^{2} \times 10^{-4}$ & $n l / \min$ & $n l / m i n$ & mosmol/liter & $\%$ & $\mathrm{ml} / \mathrm{cm}^{2} \cdot \mathrm{s} \cdot \mathrm{atm} \times 10^{-\mathrm{s}}$ \\
\hline \multicolumn{7}{|c|}{ Observed by the addition of raffinose to the bath } \\
\hline 1 & 4.28 & 11.58 & +0.21 & 224 & -2.1 & 0.142 \\
\hline 2 & 4.34 & 13.61 & -0.05 & 220 & -1.0 & -0.034 \\
\hline 3 & 6.84 & 9.62 & +0.17 & 228 & -0.7 & 0.070 \\
\hline 4 & 6.32 & 11.69 & -0.01 & 270 & +3.7 & -0.004 \\
\hline 5 & 8.20 & 11.14 & -0.16 & 262 & +6.7 & -0.049 \\
\hline 6 & 6.91 & 17.34 & -0.13 & 228 & +2.4 & -0.053 \\
\hline Mean & 6.15 & 12.50 & +0.05 & 239 & +1.5 & +0.012 \\
\hline $\mathrm{SE}$ & 0.58 & 1.00 & 0.06 & 8 & 1.3 & 0.029 \\
\hline \multicolumn{7}{|c|}{ Observed by the addition of $\mathrm{NaCl}$ to the bath } \\
\hline 1 & 2.90 & 19.00 & 0.00 & 263 & +0.7 & 0.000 \\
\hline 2 & 2.90 & 25.90 & -0.20 & 234 & +6.1 & -0.214 \\
\hline 3 & 5.53 & 16.00 & -0.20 & 281 & +3.2 & -0.084 \\
\hline 4 & 4.34 & 10.60 & +0.10 & 205 & 0.0 & +0.073 \\
\hline 5 & 3.95 & 14.00 & +0.02 & 177 & +1.5 & +0.018 \\
\hline Mean & 3.92 & 17.10 & -0.06 & 232 & +2.3 & -0.041 \\
\hline $\mathrm{SE}$ & 0.44 & 2.32 & 0.05 & 17 & 0.97 & 0.045 \\
\hline
\end{tabular}

$V_{i}$, perfusion rate; $J_{v}$, difference in net reabsorption between control periods (isosmotic bath) and when 230 mosmol of raffinose or $\mathrm{NaCl}$ were added to the bath.

(lumen negative), and for sodium it is $+6.43 \pm 0.54$ $\mathrm{mV}$ (lumen positive). When these values are compared with the simultaneously measured PD (Table III), it is evident that chloride is transported against both a chemical and an electrical force, while the sodium concentration gradient can be explained largely by passive forces, in that the observed $\mathrm{PD}, 6.3 \pm 0.5 \mathrm{mV}$ is not statistically different from the Nernst equilibrium PD, $6.43 \pm 0.54 \mathrm{mV}(P>0.6)$.

Net transport of solute. Net transport of solute was examined by measuring the ability of the isolated thick ascending limb to decrease the osmolality of the per-

TABLE III

Sodium and Chloride Transport as Compared with the Equilibrium Potential Calculated by the Nernst Equation

\begin{tabular}{|c|c|c|c|c|c|c|c|c|c|c|}
\hline \multirow[b]{2}{*}{ Exp. } & \multirow{2}{*}{$\begin{array}{l}\text { Tubular } \\
\text { length }\end{array}$} & \multirow[b]{2}{*}{$V_{i}$} & \multirow[b]{2}{*}{$V_{r}$} & \multicolumn{2}{|c|}{$\mathrm{Na}$} & \multirow[b]{2}{*}{ Eequil } & \multicolumn{2}{|c|}{$\mathrm{Cl}$} & \multirow[b]{2}{*}{$E_{\text {equil }}$} & \multirow{2}{*}{$\begin{array}{c}\text { PD } \\
\text { observed }\end{array}$} \\
\hline & & & & $C / p$ & $C / b$ & & $C / p$ & $C / b$ & & \\
\hline & $m m$ & $n l / m i n$ & $n l / m i n$ & & & $m V$ & & & $m V$ & $m V$ \\
\hline 1 & 0.70 & 0.40 & -0.01 & 0.94 & 0.82 & +5.30 & 0.96 & 0.85 & -4.34 & +3.7 \\
\hline 2 & 0.95 & 1.10 & -0.01 & 0.89 & 0.85 & +4.34 & 0.83 & 0.82 & -5.30 & +7.0 \\
\hline 3 & 1.20 & 0.48 & -0.03 & 0.87 & 0.74 & +8.04 & 0.78 & 0.67 & -10.69 & +5.8 \\
\hline 4 & 0.70 & 0.61 & +0.01 & 0.89 & 0.77 & +6.98 & 0.86 & 0.73 & -8.40 & +9.4 \\
\hline 5 & 0.95 & 0.17 & -0.03 & 0.85 & 0.79 & +6.29 & 0.75 & 0.71 & -9.14 & +5.8 \\
\hline 6 & 1.20 & 1.86 & -0.10 & 0.65 & 0.77 & +6.98 & 0.68 & 0.80 & -5.96 & +6.6 \\
\hline 7 & 1.20 & 0.72 & +0.02 & 0.69 & 0.71 & +9.16 & 0.73 & 0.76 & -7.32 & +7.0 \\
\hline 8 & 0.70 & 1.04 & -0.03 & 0.82 & 0.85 & +4.34 & 0.84 & 0.85 & -4.34 & +5.1 \\
\hline Mean & 0.95 & 0.80 & -0.02 & 0.82 & 0.79 & +6.43 & 0.80 & 0.77 & -6.94 & 6.3 \\
\hline SE & & 0.18 & 0.01 & 0.03 & 0.02 & 0.57 & 0.03 & 0.02 & 0.77 & 0.5 \\
\hline
\end{tabular}

$V_{i}$, periusion rate; $V_{r}$, net water reabsorption; $C / p$, collected and perfused fluid concentration ratio; $C / b$, collected and bath fluid concentration ratio; $E_{\text {equil }}$, equilibrium potential calculated by the Nernst equation; PD observed, transtubular PD observed during the experiment. 


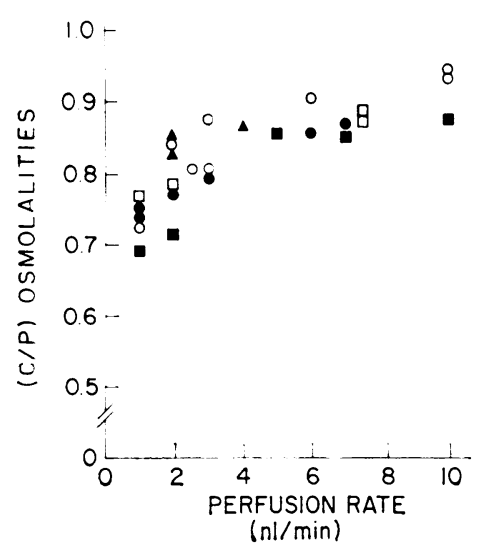

Figure 2 The relationship of perfusion rate ( $x$-axis) to the ratio of collection to perfusion $(C / p)$ fluid osmolalities ( $y$-axis) when single isolated thick ALH were perfused at varying rates using as perfusate isosmolal ultrafiltrate of the same rabbit serum which was used for the bath. A specific symbol represent studies conducted on an individual tubule.

fusate to concentrations less than the bath under varying perfusion rates. The results of these experiments are given in Fig. 2. It is evident that when faster perfusion rates (shorter contact times) were utilized that the tubule did not decrease the osmolality of the intraluminal fluid to the same degree as when slower perfusion rates (longer contact times) were used. At slow flow rates $(1-2 \mathrm{nl} / \mathrm{min})$ the collected fluid to perfusion fluid osmolality ratio of $0.77 \pm 0.02$ is similar to that obtained in those experiments in which the collected to perfused fluid sodium and chloride concentrations were measured isotopically, Table III.

Transtubular $P D$. The transtubular $P D$ was recorded in 49 experiments in which the perfusion fluid was isosmolal ultrafiltrate of the same rabbit serum as used in the bath. These results are represented in Fig. 3 . In each case the lumen was positive with respect to the bath, reaching a steady-state value within $20-45$

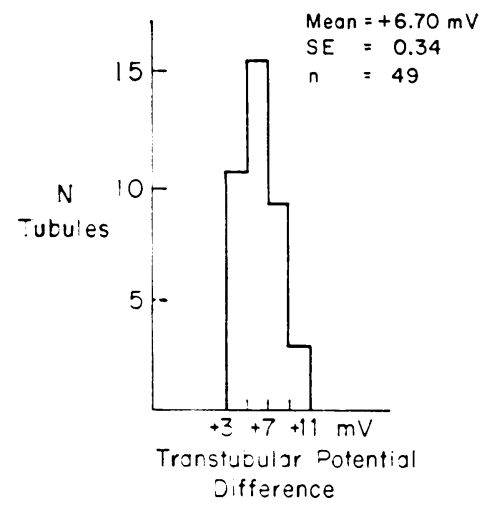

FICURE 3 Mean transtubular PD in thick ALH perfused with isosmolal ultrafiltrate of same rabbit serum as used for bath. Perfusion rate was over $2 \mathrm{nl} \cdot \mathrm{min}^{-1}$.

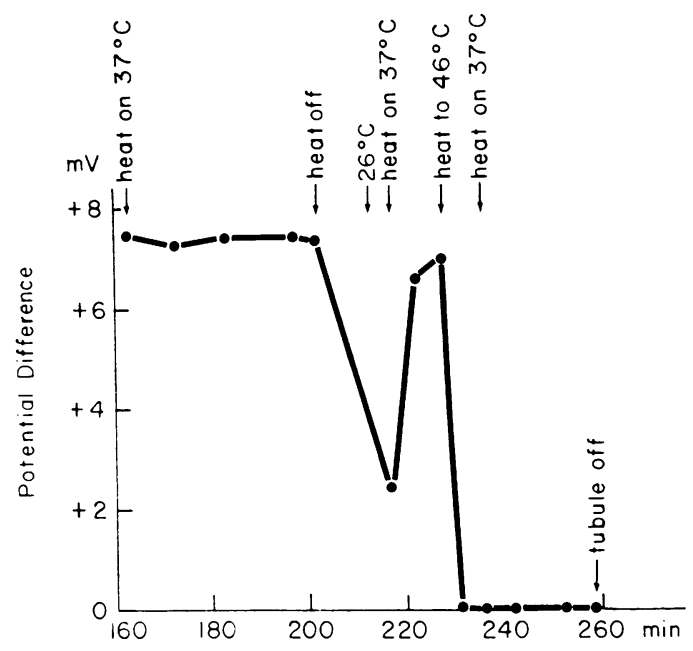

Figure 4 Response of transtubular $\mathrm{PD}$ to temperature variation of the ambient bath in a typical representative experiment.

min after the perfusion was started. The mean of all these experiments was $+6.7 \pm 0.3 \mathrm{mV}$.

Several experimental protocols were conducted to evaluate whether this $P D$ was secondary to active transport processes. There was a consistent and a reversible decrease of $\mathrm{PD}$ towards zero when bath was cooled from 37 to $26^{\circ} \mathrm{C}$ and an irreversible fall of $\mathrm{PD}$ to zero when the bath was heated to $46^{\circ} \mathrm{C}$, Fig. 4 . When $10^{-5} \mathrm{M}$ ouabain is added to the bath there was a rapid depolarization of $\mathrm{PD}$ from a control of $6.12 \pm 0.40$ $\mathrm{mV}$ to $3.22 \pm 0.41 \mathrm{mV}$, Fig. 5. The effect of ouabain was reversible in each case.

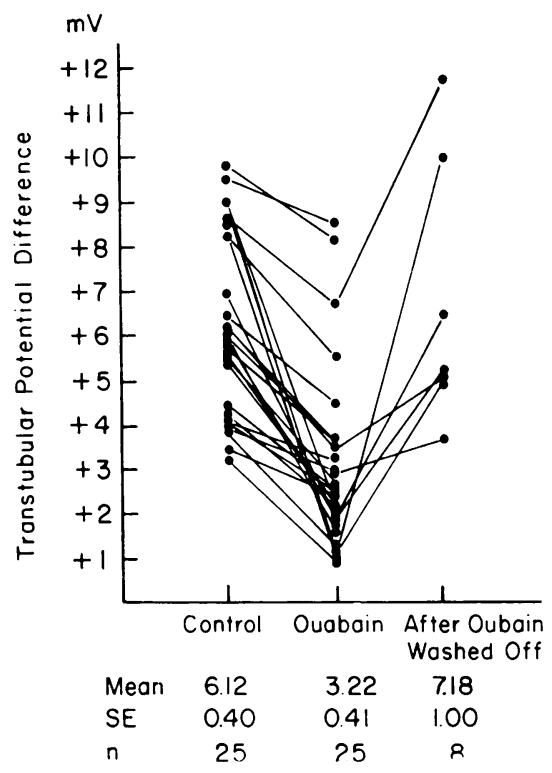

FIgURE 5 Effect on transtubular PD when $10^{-5} \mathrm{M}$ ouabain is added to the bath. 


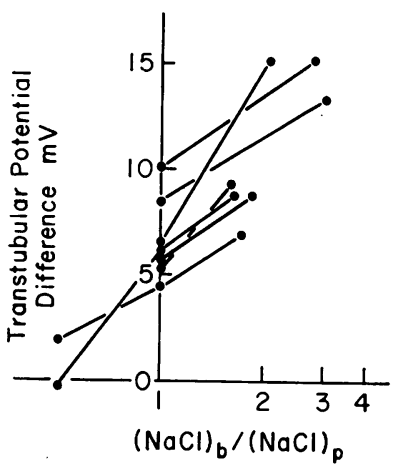

Figure 6 Response of transtubular $\mathrm{PD}$ to imposed $\mathrm{NaCl}$ concentration gradient. $(\mathrm{NaCl})_{b} /(\mathrm{NaCl})_{p}$ refers to the ratio of $\mathrm{NaCl}$ concentration in the bath as compared with the perfusate. The transtubular $\mathrm{PD}$ are corrected for liquid junction potentials.

Two possibilities have been considered concerning the origin of the transtubular PD. The first possibility is that an active neutral salt transport process generates local salt concentration gradients across the epithelial cells and that back diffusion of $\mathrm{Na}$ at faster rates than $\mathrm{Cl}$ gives rise to the luminal positivity. The second possibility is that there is an electrogenic-active chloride transport mechanism. Two types of experiments suggested that local sodium concentration gradients giving rise to diffusion potentials might play a role in the origin of the transtubular PD.

In the first series of experiments the relative permeabilities of thick ALH to $\mathrm{Na}^{+}$and $\mathrm{Cl}^{-}$was estimated by

TABLE IV

Transtubular Potential Changes $(\triangle P D)$ Resulting from Sodium or Chloride Substitution in the Bath

\begin{tabular}{ccc}
\hline & \multicolumn{2}{c}{$\Delta \mathrm{PD}$} \\
\cline { 2 - 3 } Exp. & $\begin{array}{c}\text { Substitution of NaCl by } \\
\text { choline chloride } \\
\text { (solution 1) }\end{array}$ & $\begin{array}{c}\text { Substitution of NaCl by } \\
\text { sodium methyl sulfate }\end{array}$ \\
\hline & $m V$ & $m V$ \\
1 & -15.6 & -3.3 \\
2 & -15.6 & -0.1 \\
3 & -13.3 & -1.6 \\
4 & -13.3 & -2.5 \\
5 & -7.3 & -2.5 \\
6 & -7.8 & -1.2 \\
7 & -7.3 & -1.5 \\
8 & -12.0 & -1.5 \\
Mean & -11.5 & -1.8 \\
SE & 1.18 & 0.32 \\
\hline
\end{tabular}

During the control period the observed PD was $+4.7 \pm 0.48 \mathrm{mV}$ when the perfusate and bath were artificial solutions similar to serum ultrafiltrate. The transtubular PD are corrected for liquid junction potentials. noting the transtubular $\mathrm{PD}$ response to an imposed $\mathrm{NaCl}$ gradient (water or $\mathrm{NaCl}$ added to the bath, Fig. 6 ), a $\mathrm{Cl}^{-}$gradient (sodium methyl sulfate added to bath, Table IV), or a $\mathrm{Na}^{+}$gradient (choline added to bath, Table IV). When $\mathrm{NaCl}$ was added to the bath there was an increase in the transtubular PD (lumen more positive) suggesting that the membrane is more permeable to $\mathrm{Na}^{+}$than to $\mathrm{Cl}^{-}$, thus allowing a faster rate of inward diffusion of positive charges. Reciprocal changes were noted in two experiments in which the peritubular $\mathrm{NaCl}$ was diluted by adding water to bath serum, Fig. 6 . When $\mathrm{NaCl}$ was replaced by $\mathrm{NaCH}_{3} \mathrm{SO}$ in the bath, there was a small decrease in observed $\mathrm{PD}$ of $1.8 \pm 0.3 \mathrm{mV}$; however, when $\mathrm{NaCl}$ was replaced by choline chloride, the changes in $\mathrm{PD}$ was $-11.5 \pm 1.2$ $\mathrm{mV}$. These results however are complicated by the presence of small liquid junction potentials, $0.5 \mathrm{mV}$ with $\mathrm{NaCH}_{3} \mathrm{SO}_{4}$ and $0.8 \mathrm{mV}$ with choline chloride (11, 12). In view of the problems associated with liquid junction potentials, we do not wish to interpret these data any further than to state that apparently sodium is more permeant than chloride across the thick ALH and that local sodium concentration gradients could in fact contribute to the transtubular PD.

In the second series of experiments the effect of perfusion rate on transtubular PD was examined in 10 tubules. Fig. 7 summarizes these results and shows that the PD remains constant from $40 \mathrm{~cm} \mathrm{H}_{2} \mathrm{O}$ (approximately $200 \mathrm{nl} / \mathrm{min}$ ) down to about $5 \mathrm{~cm} \mathrm{H} \mathrm{H}_{2} \mathrm{O}$ (mean stop-flow rate) perfusion pressure, but when stop-flow conditions are approached, the PD increases significantly. These results suggest that the magnitude of concentration gradients across the tubule exert a significant effect on the magnitude of the PD.

Although the above experiments support the possibility that local sodium concentration gradients, generated by a neutral salt transport process, could give rise to the transtubular $\mathrm{PD}$, other experiments clearly

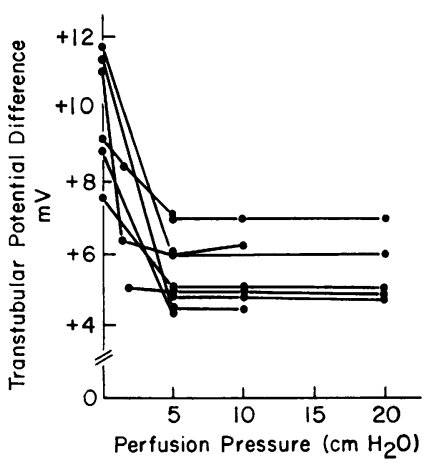

Figure 7 Effect of stop-flow perfusion on the observed transtubular PD when tubules were perfused with isosmolal ultrafiltrate of same rabbit serum as used for the bath. 
TABLE V

The Response of Transtubular Potential Difference across the Thick ALH to Complete Removal of Sodium from Bath and Perfusion Fluid*

\begin{tabular}{ccc} 
& \multicolumn{2}{c}{ PD } \\
\cline { 2 - 3 } $\begin{array}{c}\text { Perfusate: } \\
\text { Bath: }\end{array}$ & $\begin{array}{c}\text { Choline chloride } \\
\text { Choline chloride }\end{array}$ & $\begin{array}{l}\text { Serum ultrafiltrate } \\
\text { Serum }\end{array}$ \\
\hline & $m V$ & $m V$ \\
Exp. 1 & +3.5 & +4.0 \\
2 & +3.8 & +5.0 \\
3 & +2.5 & +5.6 \\
4 & +3.5 & +6.0 \\
5 & +2.6 & +5.0 \\
6 & +3.2 & +4.0 \\
7 & +3.8 & +6.6 \\
Mean & +3.27 & +5.17 \\
SE & +0.19 & +0.34 \\
\end{tabular}

* Choline chloride, solution 2 (Table I) was substituted for sodium chloride

indicate that the transtubular PD is due primarily to an electrogenic chloride pump. In these studies the effect of completely removing all sodium, by substitution with choline, from both the bath and perfusion fluid was examined in seven tubules (Table V). During control periods with normal sodium and chloride concentration in bath and perfusion fluid the PD was $+5.17 \pm 0.34$. Changing the bath and perfusion fluid to the sodium-free, choline-chloride solutions reduced the PD slightly to $3.27 \pm 0.19$. The fact that the PD fell slightly with removal of sodium could represent the contribution of localized sodium concentration gradients to the overall transtubular PD. However, the fact that even in the absence of sodium and ionic gradients there was still a significant positive PD indicates that the transtubular $\mathrm{PD}$ is due primarily to an electrogenic chloride pump.

In experiments in which chloride was removed from the bath and perfusion fluids by substitution with $\mathrm{NaCH}_{3} \mathrm{SO}_{4}$, the transtubular PD fell to zero. Although these results support the view that the $\mathrm{PD}$ is due to electrogenic transport involving chloride, these results are open to question because in the chloride-free solutions the tubular cells were observed to undergo marked anatomical changes. In addition, the PD did not return when the tubules were removed from the $\mathrm{NaCH}_{3} \mathrm{SO}$. solutions and returned to the normal chloride-containing solutions.

Isotopic permeability coefficient for sodium and chloride. The results of those experiments in which the bath to lumen permeability coefficient for ${ }^{20} \mathrm{Na}$ and ${ }^{x} \mathrm{Cl}$ were measured are summarized in Table VI. The $P_{\mathrm{Na}}$ of $6.27 \pm 0.38 \times 10^{-6} \mathrm{~cm} \cdot \mathrm{s}^{-1}$ indicates that the thick ascending limb of Henle is approximately as permeable to $\mathrm{Na}$ as is the proximal-convoluted tubule, while the $P_{\mathrm{c} 1}$ of $1.0 \pm 0.12 \times 10^{-5} \mathrm{~cm} \cdot \mathrm{s}^{-1}$ shows that the chloride permeability of the thick ALH is significantly less than the chloride permeability in the proximal convoluted tubule (13).

Bidirectional sodium flux. In this set of experiments the tubules were perfused at $8.3 \pm 0.6 \mathrm{nl} \cdot \mathrm{min}^{-1}$ with isosmolal ultrafiltrate of same rabbit serum as used in the bath. ${ }^{N a}$ was added to the perfusate and ${ }^{24} \mathrm{Na}$ was added to the bath in trace chemical amounts (Table VII). Net reabsorption of water again was not significantly different from zero, $+0.02 \pm 0.03 \mathrm{nl} \cdot \mathrm{min}^{-1}$. The unidirectional efflux of sodium was $0.591 \mathrm{neq} / \mathrm{mm}^{-1}$. $\min ^{-1}$ while the unidirectional influx was $0.351 \mathrm{neq} /$ $\mathrm{mm}^{-1} \cdot \mathrm{min}^{-1}$. The difference in these two numbers represents the net reabsorption and is equal to $0.240 \pm 0.024$ $\mathrm{neq} / \mathrm{mm} \cdot \mathrm{min}$; this value is significantly higher than $0.028 \pm 0.008 \mathrm{neq} / \mathrm{mm} \cdot \mathrm{min}$ which was obtained at a much slower perfusion rate of $0.8 \mathrm{nl} / \mathrm{min}$, Table III. This finding is in general agreement with the studies of Schnermann (14) in which it was noted that absolute $\mathrm{Na}$ reabsorption increases in the loop of Henle with increasing perfusion rate.

In absence of exchange and facilitative diffusion the measured flux ratio should equal the predicted flux ratio calculated from Ussing's equation (15):

$$
\frac{\Phi_{l b}}{\Phi_{b l}}=\frac{[\mathrm{Na}]_{l}}{[\mathrm{Na}]_{b}} \exp \frac{Z F V}{R T}
$$

where $\Phi$ is the unidirectional flux of sodium from lumen to bath $(l b)$ or bath to lumen $(b l), l$ and $b$ refer respectively to perfusate and bath; $F$ is the Faraday constant; $R$ the gas constant; $T$ absolute temperature, $Z$ is the valence of $\mathrm{Na}$ and is equal to 1 ; and $V$ equals the transtubular potential. As can be seen from the data in Table VII, the observed flux ratio is $1.71 \pm 0.09$ which is significantly higher than the ratio of $1.32 \pm 0.02$

TABLE VI

Isotopic Permeability Coefficient ${ }^{*}$ for ${ }^{22} \mathrm{Na}$ and ${ }^{36} \mathrm{Cl}$ across the Thick Medullary Ascending Limb of Henle

\begin{tabular}{ccccc}
\hline \multicolumn{2}{c}{$\approx \mathrm{Na}(\mathrm{n}=9)$} & & \multicolumn{2}{c}{$\mathrm{Cl}^{2}(\mathrm{n}=4)$} \\
\cline { 4 - 5 }$P_{\mathrm{Na}}$ & $\begin{array}{c}\text { Observed } \\
\mathrm{PD}\end{array}$ & & $P_{\mathrm{Cl}}$ & $\begin{array}{c}\text { Observed } \\
\mathrm{PD}\end{array}$ \\
\hline$\times 10^{-6} \mathrm{~cm} \cdot \mathrm{s}^{-1}$ & $m V$ & & $\times 10^{-6} \mathrm{~cm} \cdot \mathrm{s}^{-1}$ & $m V$ \\
$6.27 \pm 0.38$ & $+6.8 \pm 0.4$ & & $1.06 \pm 0.12$ & $6.8 \pm 0.9$ \\
\hline
\end{tabular}

* Perfusion fluid was isosmolal ultrafiltrate of same rabbit serum and for bath. The permeability coefficients are from bath to lumen corrected for the simultaneously measured PD by the Hodgkin-Katz equation, see text. 
TABLE VII

Effect of Ouabain on Bidirectional Fluxes in the Thick Ascending Limb

\begin{tabular}{|c|c|c|c|c|c|c|c|c|c|c|}
\hline \multirow[b]{2}{*}{ Exp. } & \multicolumn{5}{|c|}{ Control } & \multicolumn{5}{|c|}{ Ouabain } \\
\hline & $\phi_{l b}$ & $\phi_{b l}$ & $\begin{array}{c}\phi_{l b} / \phi_{b l} \\
\text { observed }\end{array}$ & $\begin{array}{c}\text { PD } \\
\text { observed }\end{array}$ & $\begin{array}{l}\phi_{l b} / \phi_{b l} \\
\text { predict. by } \\
\text { Ussing eq. }\end{array}$ & $\phi_{l b}$ & $\phi_{b l}$ & $\begin{array}{c}\phi l b / \phi_{b l} \\
\text { observed }\end{array}$ & $\begin{array}{c}\text { PD } \\
\text { observed }\end{array}$ & $\begin{array}{c}\phi_{l b} / \phi_{b l} \\
\text { predict. by } \\
\text { Ussing eq. }\end{array}$ \\
\hline & \multicolumn{5}{|c|}{ neq $/ m m$ per $\min$} & \multicolumn{5}{|c|}{$n e q / m m$ per $\min$} \\
\hline 1 & 0.711 & 0.329 & 2.16 & +7.2 & 1.31 & 0.351 & 0.233 & 1.51 & +1.7 & 1.07 \\
\hline 2 & 0.561 & 0.389 & 1.44 & +7.5 & 1.32 & 0.283 & 0.357 & 0.79 & +2.1 & 1.08 \\
\hline 3 & 0.532 & 0.370 & 1.44 & +10.1 & 1.46 & 0.285 & 0.218 & 1.31 & +4.1 & 1.17 \\
\hline 4 & 0.685 & 0.450 & 1.52 & +4.7 & 1.19 & 0.296 & 0.285 & 1.04 & +3.0 & 1.12 \\
\hline 5 & 0.506 & 0.368 & 1.38 & +7.7 & 1.33 & & & & & \\
\hline 6 & 0.579 & 0.313 & 1.85 & +5.4 & 1.22 & 0.197 & 0.152 & 1.30 & +4.0 & 1.16 \\
\hline 7 & 0.570 & 0.310 & 1.84 & +9.5 & 1.42 & & & & & \\
\hline 8 & 0.637 & 0.322 & 1.98 & +6.9 & 1.29 & 0.383 & 0.203 & 1.88 & +2.9 & 1.11 \\
\hline 9 & 0.540 & 0.309 & 1.75 & +7.1 & 1.30 & 0.307 & 0.227 & 1.35 & +6.2 & 1.26 \\
\hline Mean & 0.591 & 0.351 & 1.71 & +7.3 & 1.32 & 0.300 & 0.239 & 1.31 & +3.0 & 1.14 \\
\hline SE & 0.022 & 0.015 & 0.09 & 0.5 & 0.03 & 0.021 & 0.023 & 0.12 & 0.7 & 0.023 \\
\hline
\end{tabular}

Isotopic sodium-fluxes were measured by adding ${ }^{22} \mathrm{Na}$ to the perfusate and ${ }^{22} \mathrm{Na}$ to the bath. The perfusion rate was $8.27 \pm 0.59 \mathrm{ml} / \mathrm{min}$. $\phi_{l b}=$ flux lumen-bath, and $\phi_{b l}=$ flux bath-lumen.

$(P<0.025)$ predicted by the Ussing equation. It might be argued that the transtubular PD in the collecting end is higher than the perfusion end, since a transtubular gradient for $\mathrm{NaCl}$ has been generated. If this were the case, then the predicted ratio of 1.32 reflects a falsely low value.

The effect of ouabain is also shown in Table VII. It is of interest that ouabain decreased not only the efflux

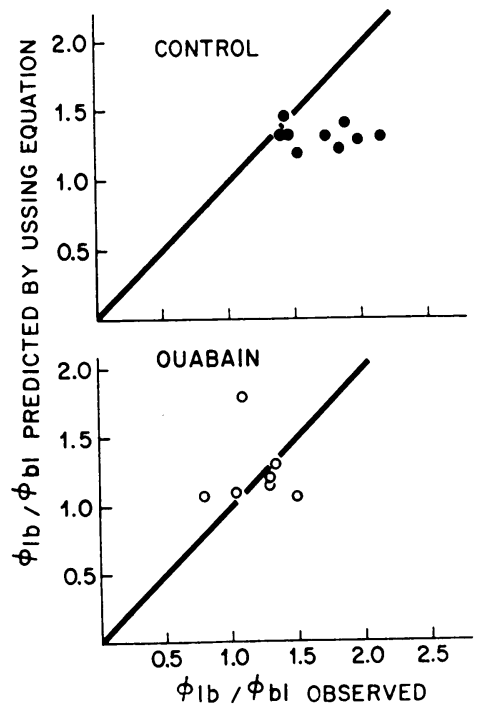

FIGURE 8 Diagramatic illustration of ouabain effect on bidirectional sodium-flux ratios. Control conditions on top panel, experimental conditions on bottom panel $\left(10^{-8} \mathrm{M}\right.$ ouabain added to the bath). $\Phi_{l b}=$ flux of sodium from lumen to bath, $\Phi_{b 1}=$ flux of sodium from bath to lumen. of $\mathrm{Na}$ from $0.591 \pm 0.022 \mathrm{neq} / \mathrm{mm}^{-1} \cdot \mathrm{min}^{-1}$ to $0.351 \pm 0.015$ $\mathrm{neq} / \mathrm{mm}^{-1} \cdot \mathrm{min}^{-1}$ but also the influx from $0.300 \pm 0.021$ $\mathrm{neq} / \mathrm{mm}^{-1} \cdot \mathrm{min}^{-1}$ to $0.239 \pm 0.023 \mathrm{neq} / \mathrm{mm}^{-1} \cdot \mathrm{min}^{-1}$. The $10^{-5} \mathrm{M}$ ouabain does not appear to have completely inhibited all transport since the transtubular PD was still $3.0 \pm 0.7 \mathrm{mV}$, Table VII, after ouabain was added to the bath. However, after ouabain the observed sodium flux ratio of $1.31 \pm 0.12$ is equal to the ratio of $1.14 \pm 0.02$ predicted by the Ussing equation $(P>0.10)$, Fig. 8. It thus appears that $\mathrm{Na}$ transport out of the thick ALH cannot be explained purely on passive equilibration according to electrochemical gradients, and that some other more complex ouabain-sensitive transport process is involved.

\section{DISCUSSION}

It is now generally accepted that the generation of concentrated urine is a consequence of osmotic equilibration of collecting duct fluid with the hypertonic medullary interstitium. Tissue analysis have shown that the greatest osmotic gradient is generated between the cortex and outer-inner medullary junction with subsequent further rise in the interstitial $\mathrm{NaCl}$ and urea concentrations as one progresses towards the papillary tip (1618). That active $\mathrm{NaCl}$ transport exists somewhere along the ascending limb of Henle has been established with the demonstration that the fluid in the early distal tubule is hypoosmotic to plasma, while the fluid obtained from the bend of the loop is hyperosmolar (19). These and subsequent micropuncture studies have not been able to further elucidate the mechanism of this $\mathrm{NaCl}$ transport in view of the inaccessibility of the thick ALH to micropuncture techniques. 
The present studies clearly demonstrate that the outer medullary thick ALH possesses the necessary properties which result in addition of more salt than water to the interstitium of outer medulla. In the above process the intraluminal fluid must become hypoosmolar with respect to the adjacent interstitium. To achieve this, the tubule must possess the capacity for active solute transport while being impermeable to osmotic flow of water so that the generated osmotic gradients are not dissipated by passive diffusion of either salt or water down their respective concentration gradients. In these studies it was shown that the thick ALH in fact is totally water impermeant when either $230 \mathrm{mosmol} /$ liter of raffinose or $\mathrm{NaCl}$ gradient is imposed on it, Table II. In addition, it was shown that the tubule can transport salt in excess of water to generate hypoosmolar intraluminal fluid, Table III, when perfused with isosmolar ultrafiltrate of the same serum as used in the bath. Under our experimental conditions, the collected fluid osmolarity was only decreased to approximately $80 \%$ of the perfusion and bath osmolarities, Fig. 2. This value clearly is not as low as noted in the early distal tubule in vivo micropuncture samples (2). It is not clear from the present studies whether the rabbit has the same capacity to generate as high osmotic gradients as noted in other mammals, or whether the cortical TAL has a further capacity to decrease the intraluminal osmolarity to such low levels as observed in vivo with other mammals (20).

The mechanism by which salt is actively transported out of the thick ALH might represent either primary cation or primary anion transport with the other ion being coupled to the electrochemical forces generated by the primary ion pump. In the previous studies in which the transtubular PD has been studied utilizing the in vitro microperfusion technique the transtubular $P D$ was found to be negative in the proximal convoluted tubule $(8,21)$, zero in the descending limb of Henle (5), and negative in cortical-collecting duct (22). In the present study it was determined that the transtubular $\mathrm{PD}$ in the outer medullary thick ascending limb of Henle was such that the lumen was always positive with respect to the bath when these segments were perfused in vitro with ultrafiltrate isosmolal to the bathing serum. The mean $\mathrm{PD}$ was $+6.7 \pm 0.3 \mathrm{mV}$. That this $\mathrm{PD}$ is secondary to active transport processes is supported by the findings that it is reversibly decreased in magnitude by: $(a)$ cooling the bath from 37 to $23^{\circ} \mathrm{C}$, and $(b)$ by addition of $10^{-5} \mathrm{M}$ ouabain to the bath. The contribution of streaming potential to the observed transtubular $\mathrm{PD}$ must be negligible in absence of transtubular water flow.

The present studies suggest that the principal ion which is actively transported in the thick ascending limb of Henle is the chloride ion since it was shown that chloride is transported against both an electrical and a chemical concentration gradient. Previously Rector and Clapp (23) have put forth evidence suggesting that the distal tubule of rat is capable of active chloride reabsorption even though its normal free-flow transmembrane PD was oriented in such a fashion that the luminal side was $-60 \mathrm{mV}$ with respect to peritubular fluid. Similarly, active chloride transport has been previously demonstrated in the cornea of rabbit (24), isolated rabbit oviduct (25), and the toad bladder (26). Although the reabsorption of chloride against steep electrochemical gradients and the presence of a positive transtubular PD strongly suggest the existence of an electrogenic chloride pump, the alternative possibility of a neutral $\mathrm{NaCl}$ pump) generating local $\mathrm{NaCl}$ concentration gradients within the membrane and a secondary positive diffusion $\mathrm{PD}$ had to be considered. The fact that positive transtubular $P D$ persisted when $\mathrm{Na}$ was completely removed from both the perfusion solution and bath by substitution with choline clearly indicate that an electrogenic chloride pump is the primary source of the transtubular $\mathrm{PD}$ in the thick ALH. However, several observations suggest that localized sodium concentration gradients can also generate diffusion $\mathrm{PD}$ which are superimposed on the basic underlying electrogenic process. These observations are: (a) the thick ALH is approximately three times more permeable to $\mathrm{Na}$ than to $\mathrm{Cl}$ as estimated both electrically (Table IV) and isotopically (Table VI) ; (b) stop-flow conditions which would amplify transtubular concentration gradients also increase transtubular $\mathrm{PD}$; $(c)$ removal of $\mathrm{Na}$ by choline chloride substitution, although not obliterating the positive transtubular $\mathrm{PD}$, does reduce it by about $37 \%$. Thus the positive transtubular $\mathrm{PD}$ appears to originate primarily from an active electrogenic chloride transport process plus small diffusion PD originating from small localized sodium concentration gradients.

In contrast to chloride, the mechanism of sodium transport by the thick ALH seems less clear. It is tempting to postulate that all of the $\mathrm{Na}$ transport is simply passive diffusion down an electrical gradient generated by chloride transport. However, as was pointed out earlier in reference to data in Table VII, the observed isotopic flux ratio is greater than the predicted by Ussing's equation, thus leading to the conclusion that another mechanism for $\mathrm{Na}$ transport probably exists which is more complex than just simple diffusion down an electrical potential gradient.

The effect of ouabain when added to the bath is interesting in that it not only decreases efflux of $\mathrm{Na}$ and $\mathrm{Cl}$, but also decreases the influx of $\mathrm{Na}$, Table VII. Thus it was shown in these studies that ouabain affects both the active and passive membrane characteristics of the thick ALH. It is now well established that ouabain inhibits the Na-K ATPase (27) and is present in sig- 
nificant quantities in the outer medulla where the thick ascending limb of Henle was dissected from (28). One possible explanation of ouabain effect is that it inhibits the active chloride pump per se as has been suggested for the isolated oviduct (25), since it decreased the transmembrane PD and almost abolished the chloride efflux completely. However, since ouabain decreased the passive permeability coefficient of $\mathrm{Na}$, its effects must be more complex than simply being inhibitory against an active transport mechanism. Ouabain has also been noted to decrease the passive permeability to $\mathrm{Na}$ in frog skin (29) and red cells (27). However, it has also been noted that ouabain may decrease transport of many other substances such as iodine and amino acids so it is not at all clear whether ouabain exerts its effect on these other Na-K ATPase-independent transport systems, or whether the transport of these other compounds are somehow coupled to $\mathrm{Na}-\mathrm{K}$ transport (27). Similarly, in our studies it appears that ouabain may exert its effect by more complex mechanisms than simply inhibiting the Na-K ATPase. Alternatively, it is possible to argue that all of our ouabain effects are secondary to nonspecific changes in intracellular constituents associated with inhibition of ATPase on the peritubular surface.

In previous clearance studies from this laboratory it has been shown that the rate of both free-water formation during water diuresis $(30)$ and $\mathrm{T}^{\mathbf{c}}{ }_{\mathrm{H}_{2} \mathrm{O}}$ reabsorption during hydropenia (31) are dependent on the rate of delivery of $\mathrm{NaCl}$ out of the proximal tubule, and not other sodium salts such as $\mathrm{NaHCO}_{3}$. These studies suggested that only $\mathrm{NaCl}$, and not $\mathrm{NaHCO}_{3}$ could be reabsorbed in the loop, but they were unable to differentiate whether $\mathrm{Na}^{+}$or $\mathrm{Cl}^{-}$was the actively transported ion. The current studies would suggest that it is the $\mathrm{Cl}^{-}$ion which is important for active reabsorption of salt out of the thick ALH. Thus, the primary solute reabsorption in the thick ALH is fundamentally of different nature than that postulated for the proximal convoluted tubule where it is theorized that one of the principal driving forces for fluid reabsorption is $\mathrm{NaHCO}_{3}$ transport (32). It is interesting to speculate that it is this fundamental difference in the basic properties in proximal and thick ALH transport mechanisms which accounts for localization of noncarbonic anhydrase inhibitory diuretics to the thick ALH.

In summary, the present studies have directly shown that the medullary thick ALH is water impermeable while having the capacity for active outward solute transport. This is consistent with the numerous micropuncture studies showing the early distal fluid to be hypoosmolar, and directly identifies at least one segment which is capable of providing energy, the single effect, which contributes to the operation of the countercurrent multiplication system.

\section{ACKNOWLEDGMENTS}

This research was supported by U. S. Public Health Service Program Grant PO1 HE 11662, National Institute of Arthritis and Metabolic Diseases Research Grant 1 RO1 AM 14677-91, and Dallas Chapter (Texas Affiliate) of the American Heart Association.

\section{REFERENCES}

1. Ullrich, K. J., B. Schmidt-Nielsen, R. O'Dell, G. Peh ling, C. W. Gottschalk, W. E. Lassiter, and M. Mylle 1963. Micropuncture study of composition of proximal and distal tubular fluid in rat kidney. Am. J. Physiol. 204: 527.

2. Malnic, G., R. M. Klose, and G. Giebisch. 1966. Micropuncture study of distal tubular potassium and sodium transport in rat nephron. Am. J. Physiol. 211: 529.

3. Windhager, E. E., and G. Giebisch. 1961. Micropuncture study of renal tubular transfer of sodium chloride in the rat. Am. J. Physiol. 200: 581.

4. Clapp, J. R., and R. R. Robinson. 1966. Osmolality of distal tubular fluid in the dog. J. Clin. Invest. 45: 1847.

5. Kokko, J. P. 1970. Sodium chloride and water transport in the descending limb of Henle. J. Clin. Invest. 49: 1838.

6. Grantham, J., M. B. Burg, and J. Orloff. 1970. The nature of transtubular $\mathrm{Na}$ and $\mathrm{K}$ transport in isolated renal collecting tubules. J. Clin. Invest. 49: 1815.

7. Kokko, J. P. 1972. Urea transport in the proximal tubule and the descending limb of Henle. J. Clin. Invest. 51: 1999.

8. Kokko, J. P., and F. C. Rector, Jr. 1971. Flow dependence of transtubular potential difference in isolated perfused segments of rabbit proximal convoluted tubule. J. Clin. Invest. 50: 2745.

9. Imai, M., and J. P. Kokko. 1972. Effect of peritubular protein concentration on reabsorption of sodium and water in isolated perfused proximal tubules. J. Clin. Invest. $51: 314$.

10. Hodgkin, A. L., and B. Katz. 1949. The effect of sodium ions on the electrical activity of the giant axon of the squid. J. Physiol (Lond.). 108: 37.

11. Barry, P. H., and J. M. Diamond. 1970. Junction potentials, electrode standard potentials and other problems in interpreting electrical properties of membranes. J. Membrane Biol. 3 : 93.

12. Boulpaep, E. L., and J. Seely. 1971. Electrophysiology of proximal and distal tubules in the autoperfused dog kidney. Am. J. Physiol. 221: 1084.

13. Imai, M., and J. P. Kokko. 1971. Flow dependence of proximal tubule permeability for ${ }^{22} \mathrm{Na},{ }^{80} \mathrm{Cl}$, and ${ }^{14} \mathrm{C}$ urea. Abstracts from the American Society of Nephrology. $5: 34$.

14. Schnermann, J. 1968. Microperfusion study of single short loops of Henle in rat kidney. Pfluegers Arch. Gesamte. Physiol. Menschen Tiere. 300: 255.

15. Curran, P. F., and S. G. Schultz. 1968. Transport across membranes: general principles. Handb. Physiol. 3(Sect. 6) : 1217.

16. Ullrich, K. J., and K. H. Jarausch. 1956. Untersuchungen zum Problem der Harkonzentrierung und verdunnung. Über die Verteilung von Elektrolyten ( $\mathrm{Na}$, $\mathrm{K}, \mathrm{Ca}, \mathrm{Mg}, \mathrm{Cl}$, anorg. Phosphat), Harnstoff, Aminosauren und exogenem Kreatinin in Rinde und Mark der Hundeniere bei verschiedenen Diuresezustanden. Pfluegers Arch. 262 : 537. 
17. Levitin, H., A. Goodman, G. Pigeon, and F. H. Epstein. 1962. Composition of the renal medulla during water diuresis. J. Clin. Invest. 41: 1145.

18. Valtin, H. 1966. Sequestration of urea and nonurea solutes in renal tissues of rats with hereditary hypothalamic diabetes insipidus. Effect of vasopressin and dehydration on the countercurrent mechanism. J. Clin. Invest. 45: 337.

19. Gottschalk, C. W., W. E. Lassiter, M. Mylle, K. J. Ullrich, B. Schmidt-Nielsen, R. O'Dell, and G. Pehling. 1963. Micropuncture study of composition of loop of Henle fluid in desert rodents. Am. J. Physiol. 204: 532.

20. Bennett, C. M., Jr., R. Clapp, and R. W. Berliner. 1967. Micropuncture of the proximal and distal tubule in the dog. Am. J. Physiol. 213 : 1254.

21. Burg, M. B., and J. Orloff. 1970. Electrical potential difference across proximal convoluted tubules. $\mathrm{Am}$. $\mathrm{J}$. Physiol. 219 : 1714.

22. Burg, M. B., L. Isaacson, J. Grantham, and J. Orloff. 1968. Electrical properties of isolated perfused rabbit tubules. Am. J. Physiol. 215 : 788.

23. Rector, F. C., Jr., and J. R. Clapp. 1962. Evidence for active chloride reabsorption in the distal renal tubule of the rat. J. Clin. Invest. 41: 101.

24. Zadunaisky, J. A. 1966. Active transport of chloride in the frog cornea. Am. J. Physiol. $211: 506$.
25. Brunton, W. J., and R. L. Brinster. 1971. Active chloride transport in the isolated rabbit oviduct. Am. J. Physiol. $221: 658$.

26. Finn, A. L., J. S. Handler, and J. Orloff. 1967. Active chloride transport in the isolated toad bladder. Am. J. Physiol. 213: 179.

27. Glynn, I. M. 1964. The action of cardiac glycosides on ion movements. Pharmacol. Rev. 16: 381 .

28. Schmidt, V., and U. C. Dubach. 1969. Activity of $\left(\mathrm{Na}^{+} \mathrm{K}^{+}\right)$-stimulated adenositriphosphatase in the rat nephron. Pfluegers Arch. Gesamte. Physiol. Menschen Tiere. 306: 219.

29. MacRobbie. E. A., and H. H. Ussing. 1961. Osmotic behaviour of the epithelial cells of frog skin. Acta Physiol. Scand. 53: 348.

30. Rosin, J. M., M. A. Katz, F. C. Rector, Jr., and D. W. Seldin. 1970. Acetazolamide in studying sodium reabsorption in diluting segment. Am. J. Physiol. 219:1731.

31. Wallin, J. D., J. P. Brennan, D. L. Long, S. L. Aronoff, F. C. Rector, Jr., and D. W Seldin. 1971. The chloride dependence of free-water reabsorption in the dog. Abstracts from the American Society of Nephrology. $5: 87$.

32. Kokko, J. P., F. C. Rector, Jr., and D. W. Seldin. 1970. Mechanism of salt and water reabsorption in proximal convoluted tubule. Abstracts from the American Society of Nephrology. $4: 42$. 